\title{
LEYENDA MORISCA DE IBRAHIM
}

" "Cuerpo de Dios, que esto es cosa de moros ¡" fue la reacción de Baltasar Ortiz, posadero y "dezmero del puerto de la villa de Arcos" al leer por vez primera el texto que voy a estudiar. Los papeles en cuestión los había encontrado en una alacena en la pared de una casa que pertenecía a una familia de moriscos de Arcos (provincia de Soria). El dueño del pequeño manuscrito era un tal Jerónimo Pintor, y en el proceso inquisitorial que se le siguió (Archivo diocesano de Cuenca, leg. 237, núm. 3072) se relatan detalladamente las circunstancias del descubrimiento (ocurrido en 1568), y además se nos conserva el peligroso librito (cada una de sus hojas lleva como prueba de su autenticidad las iniciales de tres de los que estaban presentes cuando se encontró). Este pequeño par de cuadernillos de $10 \times 14.3 \mathrm{cms}$, apenas merece llamarse manuscrito. Cirac, en su Registro de los documentos del Santo Oficio de Cuenca y de Sigüenza, Cuenca, 1965, los describe como unos "capítulos del Corán en su romance" (idea sugerida, sin duda, por las acusaciones hechas por los inquisidores en el curso del proceso), pero, como veremos, la identificación del texto no es acertada. Los folios de los cuadernillos, sin numerar, son diecinueve en total; dieciocho de ellos están intactos, pero del último sólo se conserva menos de la mitad. Sin desencuardenar el manuscrito del proceso entero, resulta imposible saber exactamente de qué manera se relacionan los folios entre sí, pero se ve claramente que hay dos cuadernillos diferentes, el primero de los cuales tiene diez hojas, el segundo nueve. Se sabe, por las pruebas que se presentaron durante el proceso, que en tal estado estaban los documentos cuando se descubrieron.

Detalles del juicio indican que los cristianos viejos pudieron leer el primer cuadernillo con algo más de facilidad que el segundo, pero al examinarlos se puede ver que no fueron dos las manos que los escribieron, sino por lo menos tres. Tres también son los textos contenidos en los cuadernillos: $a$ ) un calendario abreviado, o mejor dicho, una lista de festividades correspondientes al año islámico (fols. 1-10v; el texto está completo y en el orden correcto); $b$ ) dos fragmentos de un texto religioso en el estilo hadith ("dixu Gali Ybinu Abitali") y relacionado con el día del juicio (fols. 11r, 12v y 164-174); c) un extenso fragmento de la levenda apócrifa de Ibrahim que está 
desordenado (los tex tos empiezan al pie del fol. $17 \mathrm{r}$ y continúan en el $17 \mathrm{v}, 18 \mathrm{r}-\mathrm{v}, 134-\mathrm{v}, 14 \mathrm{r}-\mathrm{v}, 15 \mathrm{r}-\mathrm{v}, 19 \mathrm{r}-\mathrm{v}$-este último folio maltratado).

Una exposición completa de los problemas lingüísticos que presentan estos textos no puede hacerse antes de que se publiquen las secciones que no están relacionadas con la leyenda de Ibrahim. (Espero publicar la sección del calendario con un manuscrito similar en caracteres árabes que se encuentra en la Biblioteca Británica). Sin embargo, es necesario mencionar aquí un rasgo poco común: la aparición de $u$ en vez de o en las palabras dixu, miedu y pluru. Puesto que el fenómeno se encuentra sólo en el fol. 19v del texto de la leyenda de Ibrahim, el lector podría suponer que ese rasgo es un error de imprenta, o un error mío al hacer la transcripción, o inclusive un desliz cometido por el morisco del siglo XVI. No es así: estas formas se encuentran también en los textos $a$ y $b$; la frecuencia de su aparición varía, de manera esporádica. Los pocos ejemplos que se encuentran en el folio 19 podrían explicarse aisladamente como representaciones gráficas de una o final muy cerrada (con pluru por la armonía vocálica), pero esa explicación no es, sin duda, la correcta, porque en otros lugares $u$ también se encuentra en monosílabas (como lus, sun, 4r, y yu, 12v), en donde la pronunciación con vocal cerrada es tan poco característica de cualquier dialecto hispánico que es virtualmente imposible.

En mi opinión, no se trata aquí de un rasgo fonético de origen dialectal, sino de un rasgo grafémico que se produjo a causa de la transliteración mecánica y poco inteligente del texto en caracteres árabes. El escriba morisco debe haber tenido ante sus ojos un texto en aljamía, y al transliterarlo, a veces transcribía la $u$ breve del árabe (damma) como $u$ y otras como o. Esto explicaría la aparición esporádica del rasgo. Es notable cómo la transliteración por $u$ se encuentra más frecuentemente en palabras que tienen marcada connotación islámica, como dayunu.

Si mi explicación es correcta, el documento, a pesar de tener cierto tinte aragonés (por ejemplo, pluru, citado arriba), en general, ofrece un ejemplo normal del castellano arabizado que usaban los moriscos de Castilla y áreas limítrofes.

Esta es la historia de Ibrahim en el texto del manuscrito de Cuenca:

\section{CuENCA, LEGAjO 237, NưM. 3072}

Folio 17 recto/Bismi ylaharrahameni irrahimi fue recontado que Ybraen halizalen rogó ad Alla, y demandóle de grazia que le demostrase de sus milagros, y díxole / $17 \mathrm{v} /$ bes ya Hibrahen por la orilla del mar, y demostrarte e partida de lo que me demandas. Laora tomó Hibrahen dos tortas de pan de ordio, y tomó una cayata en su mano, y fuese fasta que llegó a la orilla de la mar. Y él, como iba su camino 
adelante, oyó un lloro y fue Ybraen enta do oyó aquel lloro, y falló, un alhabiz que fazía açala en su almihrabe, y parose Ybraen delante del / $18 \mathrm{r}$ / y esperó hasta que se diese azalen, y dixo Hibraen: - Lazalem sea sobre tú, ya onbre. Y dixo él: -Sobre tú sea el azala (sic) ya amigo del piadoso. Y dixo Hibraen: - Ya hermano ¿quién te ha hecho a saber que yo soy amigo del piadoso? Dixo: $-\mathrm{A}$ me benido rebelazión de parte de mi Señor que no me vería en este lugar sino tú. $/ 18 \mathrm{v} / \mathrm{Y}$ laora lebantose el alhabiz, y Ybrahen siguiolo fasta que llegaron el alhabiz a la mar, y lançó su caja /?/ en la mar, y entró y yba sobre el agua. Y laora parose Ybraym pasmado de aquella marabilla. Y dixo el alhabiz: - Entra, ya Ybrahem. Y entró Ybrahem de zaga del alhabiz fasta que plegaron a una isla en medio de la mar. Laora lebantose $/ 13 \mathrm{r} /$ lalhabiz y hizo azala, y no fabló a Ybrahem fasta que amaneçió, y Ybrahem de çaga del, y quando amanesció, posose y Ybrahen y pensaba en su fecho, y alęó sus ojos ental cielo, y bio un carnero que deballaba del cielo, y asentose delante de las manos del alhabiz. Y laora tomó el alhabiz una piedra y quebrola /13v/ y degolló con ella el carnero,y después firió en la piedra con otra piedra, y salla fuego, y plegó lleña, y encendiola, y puso la carne ad asar, y partiola por medio, y tomó la mitad y dixo: -Ya Ybrahem, come tú esa carne. Laora sacó Ybrahem las dos tortas de pan de ordio y dixo el alhabiz: - ¿Ya Ybrahem, /14r/ de qué se haze ese pan? Dixo Ybrahem: - Que lo labran y lo siembran y lo siegan y lo muelen y lo masan y lo cuezen. Dixo el halhabiz: -Cómete tu pan, que yo no lo e menester, ny lo conozco. Y comieron entramos fasta que acabaron el carnero. Laora tomó el alhabiz y ayuntó todos los güesos del carnero en su cuero delante de Ybrahen, y después dixo el alhabiz: - Lebantate con liçencia de Wl . Y lebantose el carnero sobre sus piedes y pidió /?/ al çielo, y Ybrahem que los miraba, y dixo al alhabiz: —Quántos años ha questás en este lugar? Dixo: - A ciento quarenta años, y no comí más de una bez en el año, y aste acaezido / $15 \mathrm{r} /$ en el día de mi pascua. Y marabillose mucho daquello que bio, y dixo Ybrahem: - Ya mi Señor, este es el milagro que me prometiste que me demostrarías. Y enbió a él y dixo: -Bes, ya Ybrahem, más adelante y berás otro milagro mayor que no ese. Y fue Ybraem su camino /15v/Y andando oyó una boz mui triste, y un ploro mui fuerte, y fue hasta donde oyó la boz, y halló una rana sobre una piedra de la mar, y deçía: - Tan glorificado es all! ! tan bendicho es all! !y tan hendicho es ga aien no me olbida en este lugar! Y laora azercose Ybrahem enta la rana y dixo /19r/: -azalen alayka ya rana y dixo la rana: -sobre ti sea el azalen ya amigo del piadoso. Y laora dixo Ibrahem: -quién te a echo a saber que yo soy amigo del piadoso dixo la rana a me benido rebelaçión de partes de mi Señor que no me bería nenguno en aqueste lugar sino tú. /19v escrito por la mano de "A" / Dixo Ibrahim:-quanto tien [po ha] questas en este lugar Dixo la rana mil años dixo Ibrahim: 
-de que te probiendas. Dixo:-Cuando amaneçe Alia con la mañana, salle aquel cada día sobre aquesta piedra una foja amarilla, y probiendome della [cada] día dixu Ybrahim. Y porque lloras pues no abe sobre tú pecadu dixu la rana:-Ye lbrahim e miedu que no llegará mi obra con lo que a fecho Allah haza gua jala de gracia, y pluru por [aquí termina el manuscrito].

Notarán los lectores que en el folio 19 se han llenado las lagunas. He cubierto estos vacíos, no a través de una reconstrucción hipotética, sino a base de un manuscrito aljamiado de la Biblioteca Nacional de Madrid, en el que se encuentra un texto casi idéntico al de Cuenca (fue editado por F. Guillén de Robles en su libro Leyendas moriscas sacadas de varios manuscritos existentes en las Bibliotecas Nacional, Real y del P. Gayangos, Madrid, 1885-1886). Este manuscrito tiene el texto más completo que he encontrado hasta hoy, pero grande fue mi sorpresa y mi placer al encontrar, también en la Biblioteca Nacional, otro manuscrito, en árabe esta vez, con otra versión, casi completa, del texto. Según yo sepa, este texto árabe no ha sido publicado hasta hoy, aunque Guillén de Robles en su Catálogo de los manuscritos árabes existentes en la Biblioteca $\mathrm{Na}$ cional de Madrid, Madrid, 1889, lo identificó claramente en la entrada siguiente: "CLXXIX Leyenda de Abraham, $4^{\circ}$ papel, falto al principio y fin, 19 fol. magrebí, 2 fol. bl. al principio;3 al fin. Comprende además varias poesías en loor de Mahoma. Procedente de la Biblioteca de Osuna".

El lector habrá observado que Guillén de Robles no hace referencia al manuscrito aljamiado publicado por él unos pocos años antes. Sospecho que el desorden de los folios en este pequeño manuscrito árabe fue tal que no le permitió reconocer la identidad (la palabra no es exagerada) de los dos textos. Debido al gran interés de las dos versiones, los publico paralelamente para que pueda verse la manera de trabajar del traductor morisco.

Téngase en cuenta que mi edición del texto aljamiado no pretende ser una transliteración. Prefiero utilizar en la medida de lo posible los recursos del sistema ortográfico español de los siglos XV y XVI, apartándome de él sólo cuando la necesidad de aclarar una posible ambigüedad fonética me obliga a ello. Allí donde el lector podría vacilar, procuro resolver sus dudas por conocidos símbolos más modernos. Me atrevo a decir que cualquiera que esté familiarizado con el español del período en cuestión y con el aljamiado, podría reconstituir con bastante exactitud el texto en caracteres árabes a partir de lo que presento en caracteres latinos (y añadiría, no hay sistema que nos permita una reversibilidad absoluta).

Debo aclarar que no pretendo que mi sistema simplificadollene todas las necesidades de todos los especialistas; pero creo que para las finalidades que me propongo, a saber comparar el texto alja- 
miado con el árabe original, la transliteración que presento resulta más fácil de leer. El que las ediciones modernas de los textos aljamiados los presenten disfrazados bajo un ropaje tan irreconocible habrá contribuido quizá a que casi nadie los lea (los textos publicados por mí hasta ahora han sido transliteraciones ortodoxas, así que soy co-responsable de este estado de cosas). Quizá, esta manera de presentar los textos pueda considerarse un experimento: espero las reacciones que se producirán. Es posible que me critiquen por haber regresado a finales del siglo XIX, cuando los editores se sentían con la libertad de alterar las palabras y formas si se consideraban difíciles, pero una crítica como ésta no sería justa ya que no he alterado nada, y las formas difíciles y poco comunes no se han cambiado. 
MADRID, B. N. 5251

يروى ان ابراهيم خليل الرحعن صلؤتالله على نبينا وطيه /

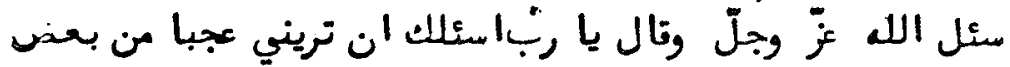

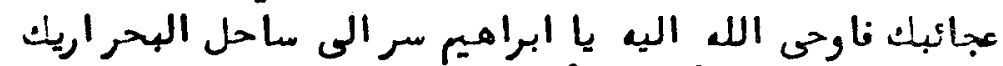

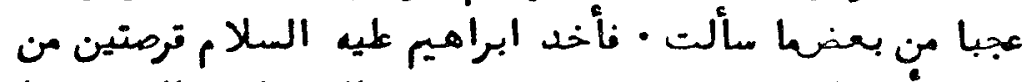

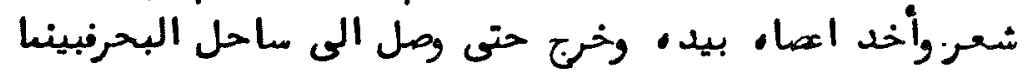

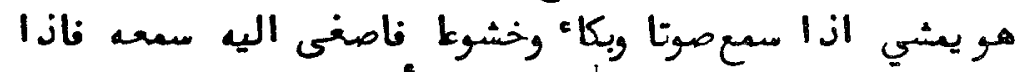

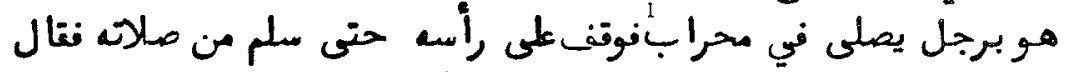

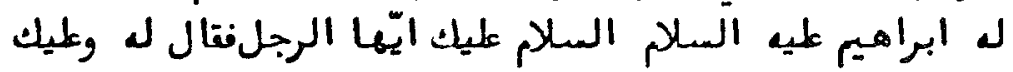

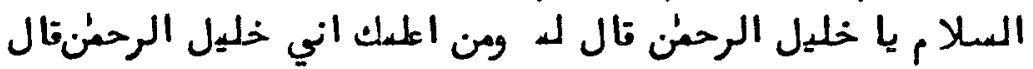

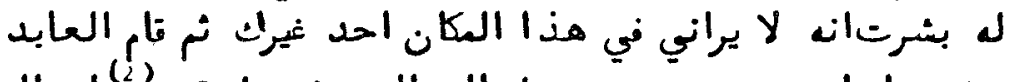

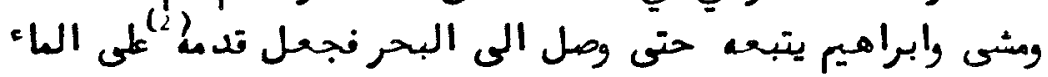

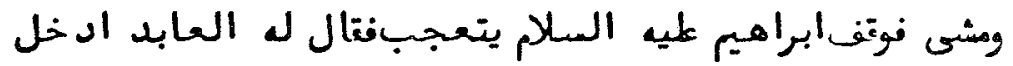

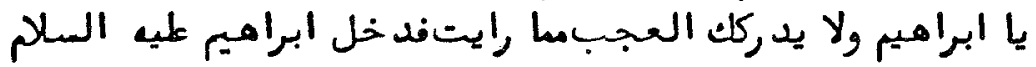

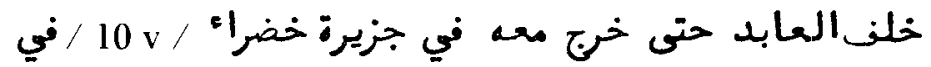

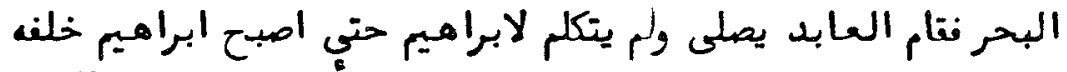

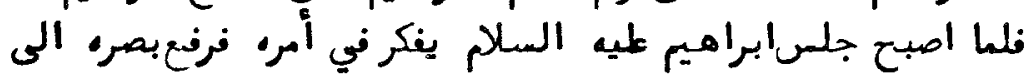

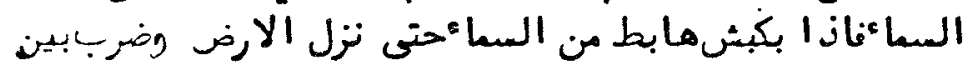

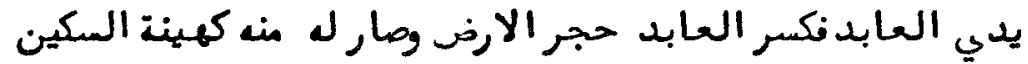

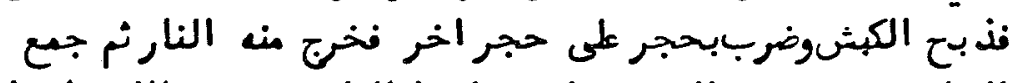

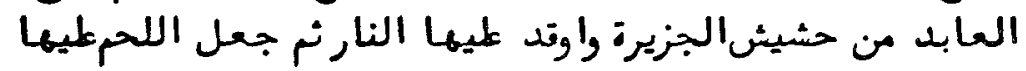

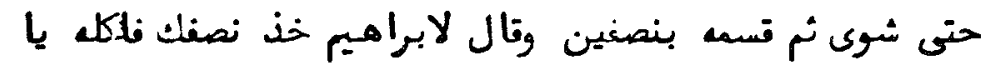

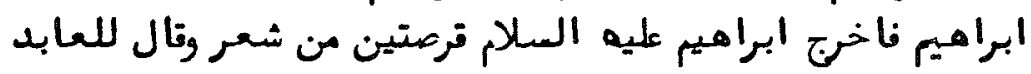

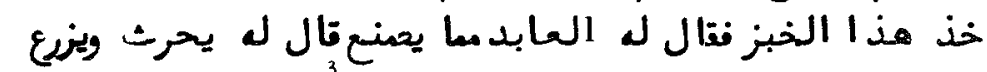

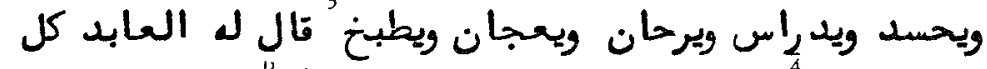

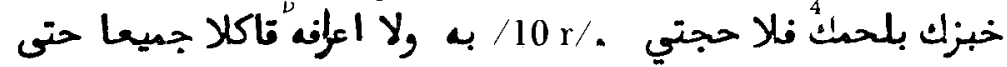

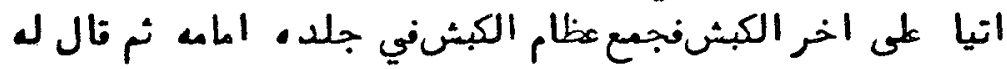

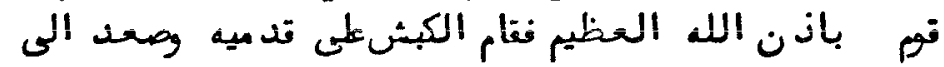

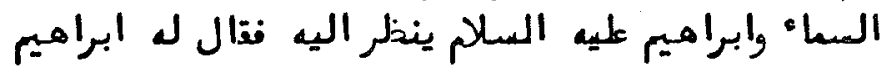


MADRID, B.N. 5313

Bismi illāhi irraḥmāni irrahīmi: este es alhadit de Ibrahīm alayhi iççalem, fue recontado que Ibrahim, "alayhi iç̧alem, rogó ada Allah que le demostrase de sus milagros y dixo Allah - Bes ye Ibrahim a la orilla de la mar, demostrarte-[é] partida de lo que demandas. Laora /133v/ tomó Ibrahim dos tortas de pan de ordio, y tomó una gayata en su mano y fuese fasta que llegó a la orilla de la mar. Y él, como iba su camino adelante, oyó un lloro. Y laora fue Ibrahim enta donde oyó la boç, y falló un al' abid que fazía assala en un almaihrab, y parose Ibrahim delante del / $114 r / y$ esperó fasta que dio așsalem, y dixo Ibrahim: -Laççalem sea sobre tú, ye al' abid, ye onbre. Y dixo él - S sbre tú sea laççalem, ye amigo del piadoso. Dixo Ibrahim: - Ye ermano, ¿quién te a fecho a saber que yo soy amigo del piadoso? - A me benido rebelaçión de parte de mi señor que no me bería en aqueste $/ 114 \mathrm{v} /$ lugar nenguno sino tú, ell amigo de Allah. Después lebantose lal'abid, y Ibrahìm sig[u]iolo fasta que llegó lalcabid a la mar, y lançó, su capa en la mar, y entró lal' abid en la mar. Y laora parose Ibrahim, pasmado de como iba sobrell agua, y marabillose mucho. Y dixo el al ${ }^{c}$ abid: -Dentra ye Ibrahím. Y entró Ibrahīm de çaga del alcabid fasta que llegó a una isla que estaba en medio de la mar. Y laora, lebantose el $a^{c}$ abid y fizo așsala, y no fabló a Ibrahìm fasta que amaneció, y Ibrahìm de çaga del, y cuando amaneció, posose y pensaba en su fecho, y alçó sus ojos al çielo y bio un carnero que deballó $/ 115 \mathrm{v} /$ del çielo y posose delante de las manos del alcabid y laora tomó al al'abid una piedra, y crebola y degolló con ella el carnero, después firió en la piedra, y salió della fuego, y llegó leña y ençendiola, y puso la carne ad asar, y partiola por medio, y dixo - /116r/ come tú esa carne. Laora sacó Ibraīm dos tortas de oan de ordio; y dixo lal`abid: - ¿De qué se fase, ye Ibrahim, ese pan? Dixole Ibrahim: -Que lo labran, y lo siembran, y lo siega, y lo muelen, y lo masan y lo cuezen, Dixo el al' abid - Come tu pan, que yo no lo e menester, ni lo conoçco. $/ 116 \mathrm{v} / \mathrm{Y}$ comieron entranbos fasta que acabaron el carnero. Laora tomó el alcabid los güesos del carnero, y ajumolos todos en su cuero delante de Ibrahim. Despues dixo el al' abid: -Lebántate con liçencia de Allah. Y laora lebantose el carnero sobre sus piedes y puyó al çielo, y Ibrahim $/ 117 \mathrm{r} /$ que lo miraba; y dixo Ibrahim el al'abid: 
8

L. P. HARVEY

NRFH, XXX

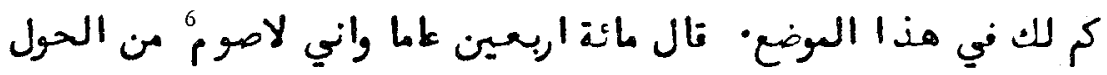

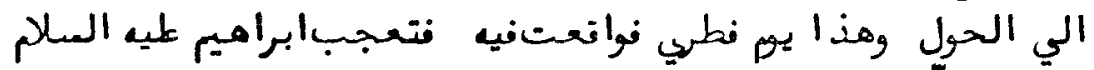

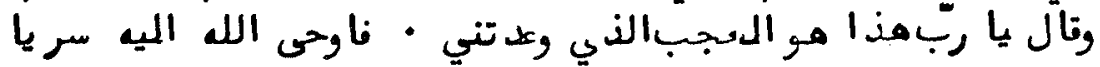

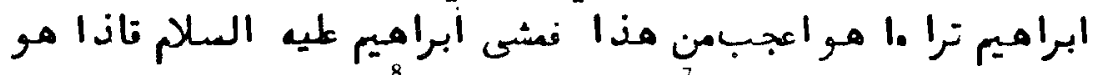

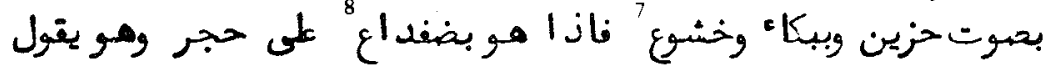

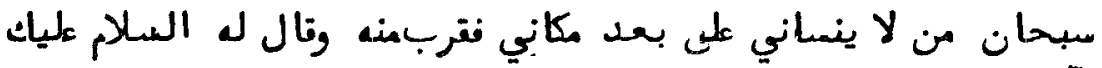

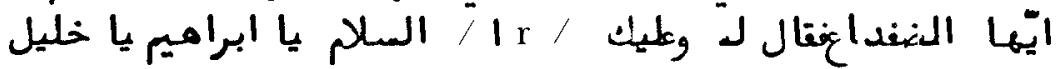

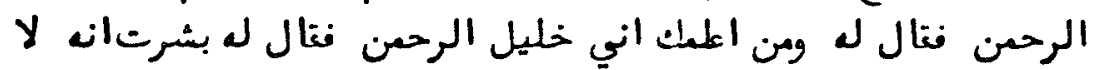

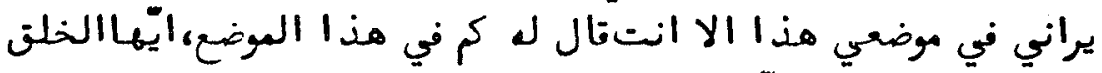

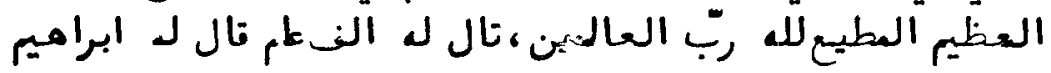

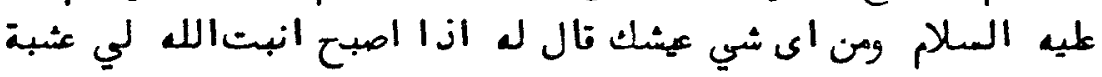

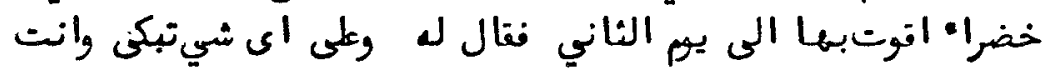

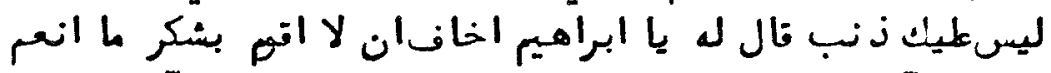

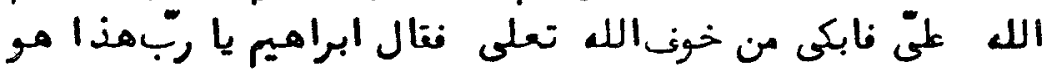

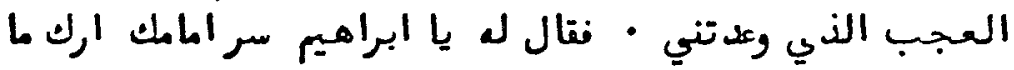

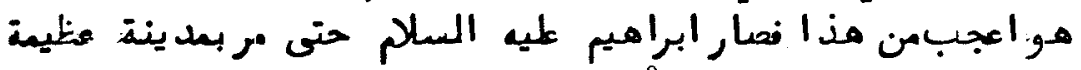

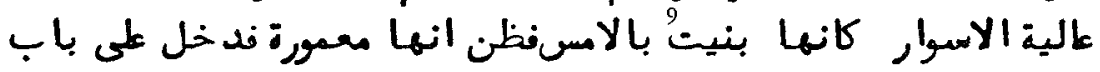

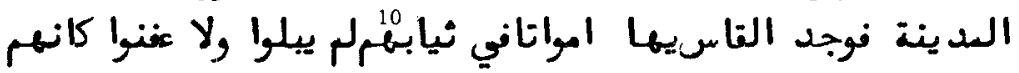

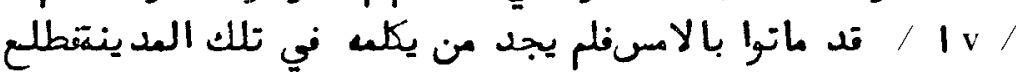

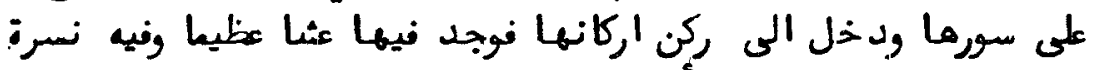

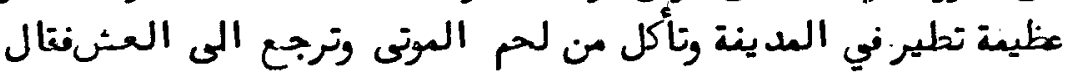

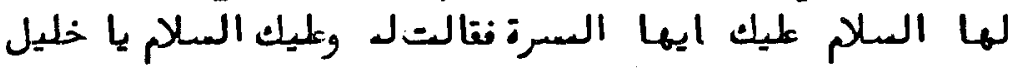

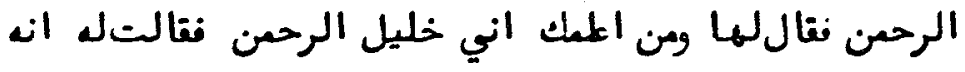


- ¿Cuantos años abe que estas aquí en este lugar? Dixo: - Abe çiento y cuarenta años, y no como más de una beç en el año, y aste açertado en el día de mi pascua. Y marabillose de aquello Ibrahim, y dixo Ibraim: $/ 117 \mathrm{v} /$-Ye mi Señor, aqueste es el milagro que me prometiste que me demostrarías. Y enbió Allah a él donde dixo: - Bes ye Ibrahim adelante, y demostrarte[é] otro milagro mayor que no ese. Y fuese Ibrahim su camino adelante, y andando coyó una boz muy triste y un lloro muy fuerte /118r/ y fue Ibrahìm enta donde oyó la boç, y falló una rana sobre una piedra en la mar, y dezía la rana: - Tan bendito es Allah!, y jtan bendito es quien no me olbida en este lugar! Y Laora acercoce Ibrahïm enta la rana y dixo: - Aççalem ' alayku (sic) ye rana. Y dixo la rana: -Sobre ti sea laççalem $/ 118 \mathrm{v} /$ ye amigo del piadoso. Y dixo Ibrahim: - ¿Quién te a fecho a saber que yo soy amigo del piadoso? Dixo la rana: -A me benido rebelaçión de partes de mi Señor que no me bería nenguno en aqueste lugar sino tú. Dixo Ibrahim: $-¿$ Cuánto abe questas en este lugar? Dixo la rana: - Abe mil años /119r/Dixo Ibrahìm: - ¿De qué te probiendas? -Cuando amaneçe Allah con la mañana, salle cada día sobre aquesta piedra una foja amarilla, y probiéndome della. Dixo Ibrahim: $-¿ Y$ por qué lloras, pues no abe sobre tú pecado? Dixo la rana: - Ye Ibrahìm, e miedo que no llegará mi obra $/ 119 \mathrm{v} /$ con lo que a fecho Allah, ' $a z a$ wa-ğalla, de graçia sobre mí, y lloró por miedo de Allah. Dixo Ibrahim: - Ye mi Señor, aqueste es el milagro que me prometiste que me demostrarías. $Y$ enbió Allah a él: - Ye Ibrahìm, bes mas adelante, y demostrarte[é] mayor milagro que no ese. Y fuese Ibrahìm más adelante, y pasó por una /120r/ çibdad muy grande y buena, torreada así como que se ubiese fra[g]guado laora. Y entró Ibrahìm por la puerta de la çibdad, y falló todas las gentes muertas, sin alqafanas sino ansí como se eran, con sus ropas. No teñían ni golian, que parece que laora abían muerto. Y no falló con quien fablar en aquella çibdad, $/ 120 \mathrm{v} /$ y subió sobre sus torres, y entró en un rincón de sus rincones, y falló en él una abe muy grande que volaba enta la çibdad, y comió las carnes de los muertos, y tornábase a su lugar. Dixo Ibrahìm. ' alayhi iççalem: -L'aççalem sea sobre tú, ye abe. Dixo ell abe: -Sobre tú sea aççalem, ye amigo $/ 121 \mathrm{r} /$ del piadoso. Dixo: - ¿Quién te a fecho a saber que yo soy amigo del piadoso? Dixo 


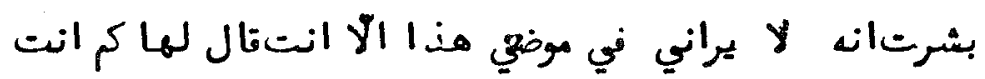

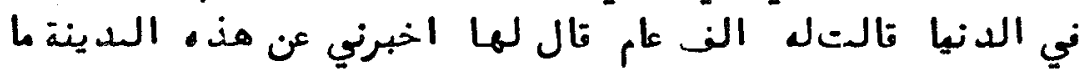

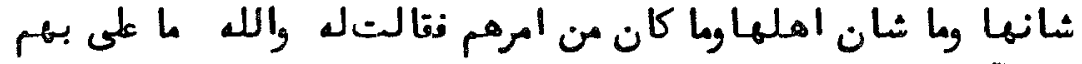

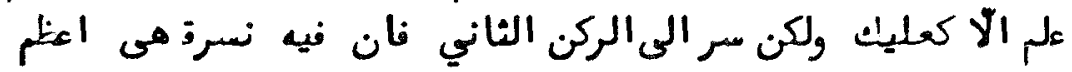

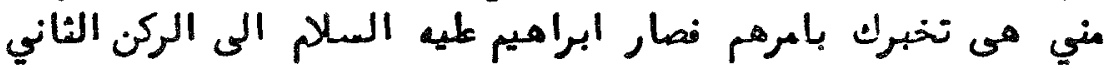

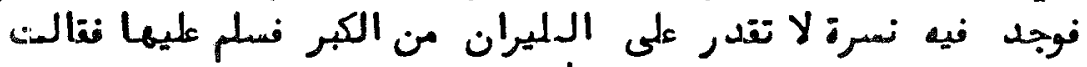

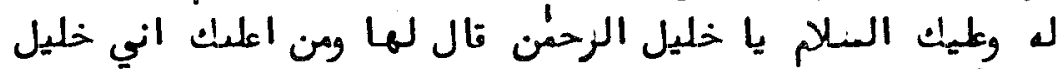

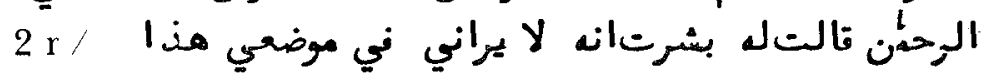

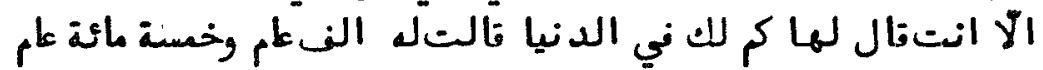

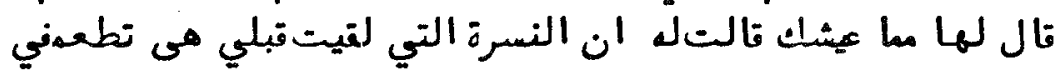

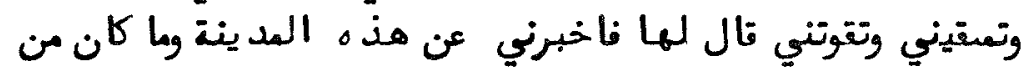

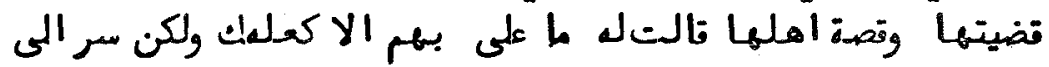

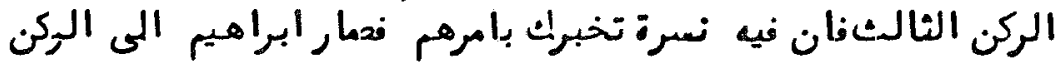

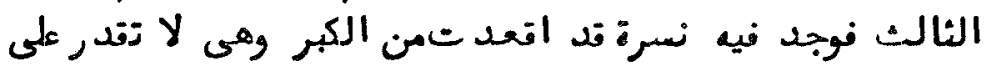

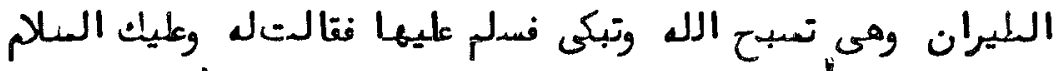

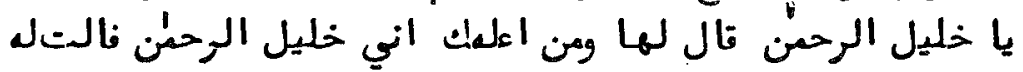

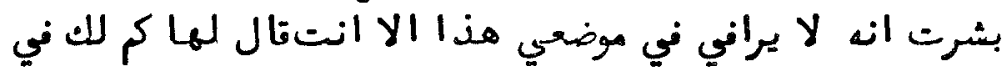

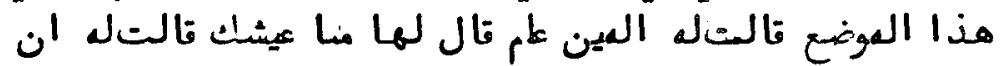

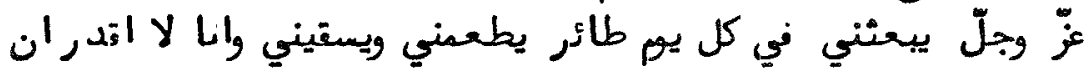

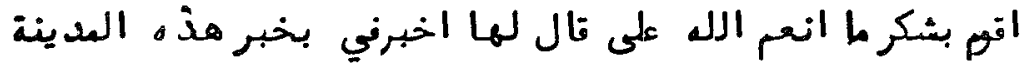

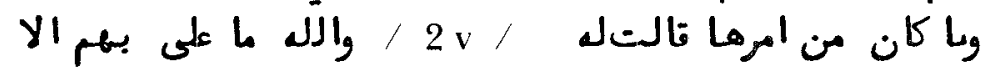

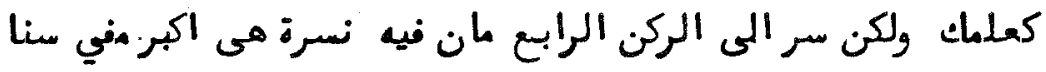

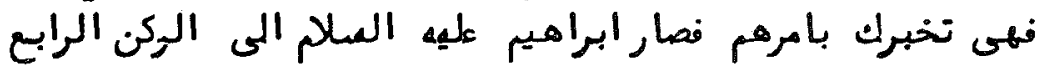

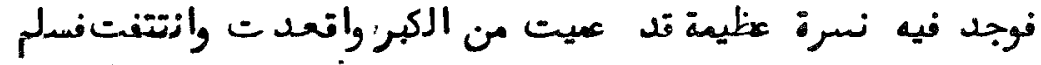

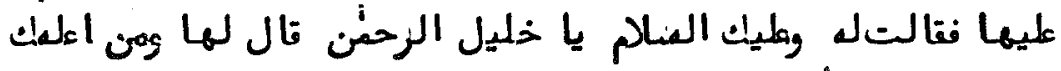

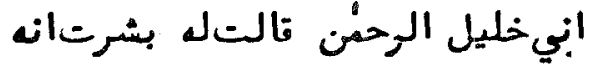


ell abe: -Albriçióme mi señor que no me beria en este lugar sino tú, ell amigo del piadoso. Y dixo Ibrahim: - ¿Cuánto abe que estás en esta adunya? Dixo ell abe: - Mil años. Dixo Ibrahim: —Ye abe, feçme a saber del fecho desta/12lv/çibdad. Dixo ella: - Por Allah, no abe a mi saber a ello, enpero bes más adelante al rincón segundo, y fallarás en él otra abe qu'es mayor que no yo, y ella te fará a saber del fecho desta çibdad. Y fuese Ibrahim al rincón segundo, y falló una abe que no podía bolar, tanto era de grande, y dio aççalem sobrella, y dixo ella: - Sobre tu sea aççalem, ye amigo del piadoso. Dixo Ibrahim: 一 ¿Quién te a fecho a saber que yo soy amigo del piadoso? Dixo ella: -Albriçióme mi señor que no me bería nenguno en este lugar sino tú. Dixo Ibrahim: - Ye abe, ¿cuánto a qu'estás en esta adunya? Dixo ell abe: -Dos mil años a. Dixo Ibrahìm: /112v/ - ¿De qué te probiendas? Dixo ella: -Aquella abe que as encontrado ante de mí, ella me trae probisión. Y dixo Ibrahim: - Feçme a saber de aquesta çibdad, y de los que están en ella? Dixo ella: - Ye Ibrahĩm, sepas que mi saber no es más que tu saber, empero bes al rincón tercero, que en él ay otra abe mas /123r/ antiga que yo, que ella te fará a asaber con su fecho. Y fuese Ibrahím al rincón terçero, y falló una abe que todo se caía, tanto era de antigua, y no podía bolar. Y ella ataçbihaba ada Allah, y lloraba, y dio açalem Ibrahìm sobrella y dixo ella: - Sobre tú sea aççalem, ye amigo del piadoso. Y dixo Ibrahim: $/ 123 \mathrm{v} /$ - ¿Quién te a fecho a saber que yo soy amigo del piadoso? Dixo: -Albriçióme mi señor que no me bería en este lugar sinon tú. Dixole: $-Y$ ¿cuánto a qu'estas en esta adunya? Dixo ella: - Tres mil años abe que estoy en ella. Y dixo Ibrahim: - ¿Qué es tu probisión? Dixo ella: -Allah tacãla /124r/ me envía cada día una abe que me da a comer y a beber, y yo no puedo lebantarme de mi lugar, loado sea Allah, mi señor. Dixo Ibrahim: - feçme a saber de aquesta çibdad, y que a seído su fecho. Dixo ella: - Por Allah, no sé dellos más que tú, ye Ibrahim, enpero bes al rincón cuarto, que en el fallarás $/ 124 \mathrm{v} /$ una abe mayor que no yo de tienpo, y ella te fará a saber dello. Y fuese Ibrahim al rincón cuarto y falló en el una abe que se abía echo ciego, tanto era de antiga, y dixo açalem sobrella, y dixo ella: - Sobre tú sea el aççalem, ye amigo del piadoso. Y dixo el: - ¿Quién te a fecho a saber que yo soy amigo del piadoso? Dixo ella: -Albriçióme /125r/mi señor 


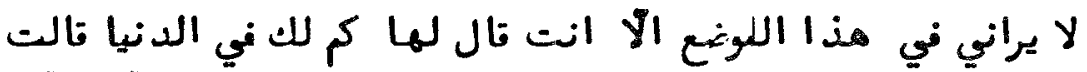

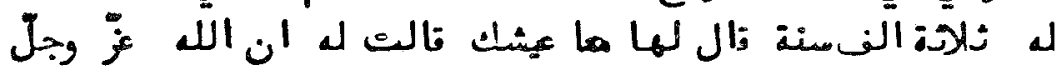

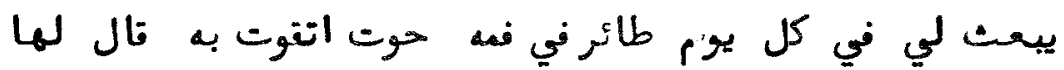

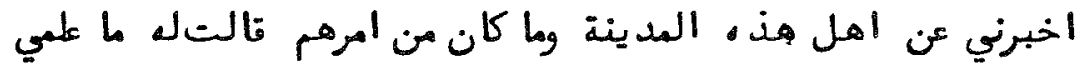

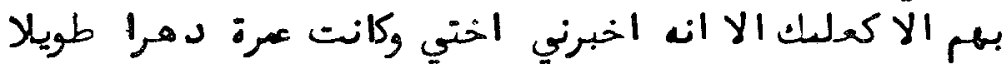

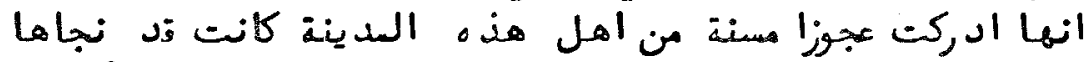

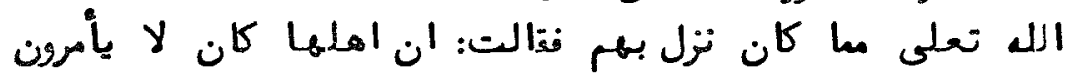

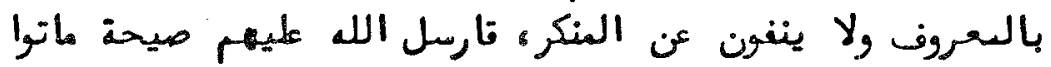

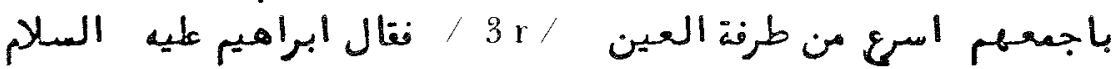

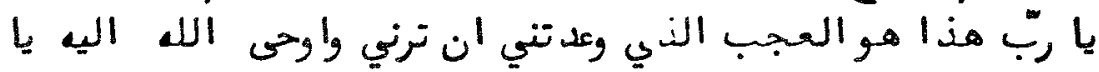

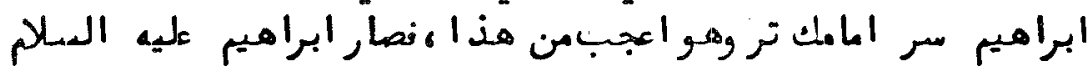

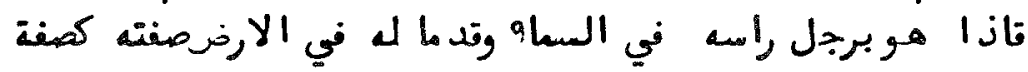

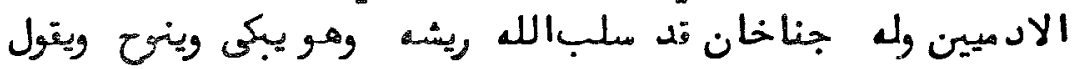

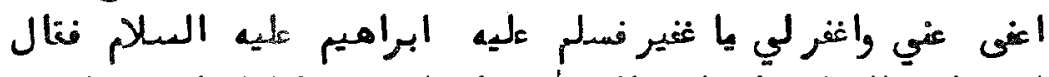

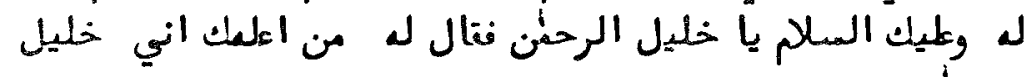

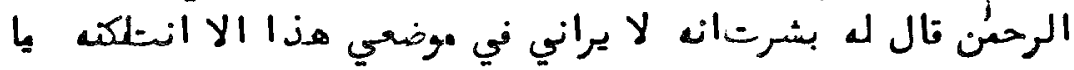

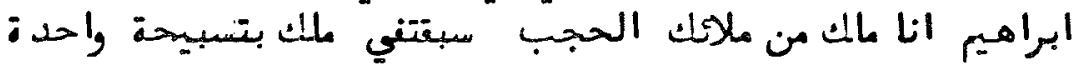

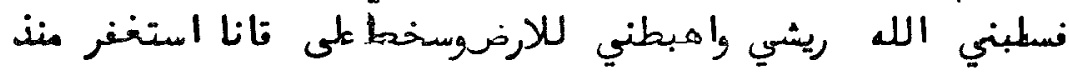

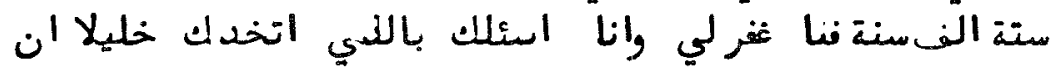

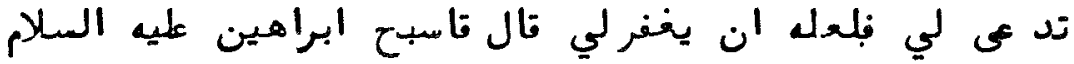

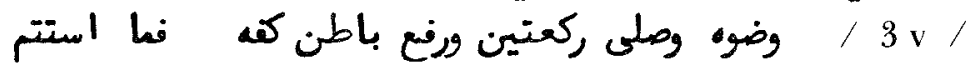

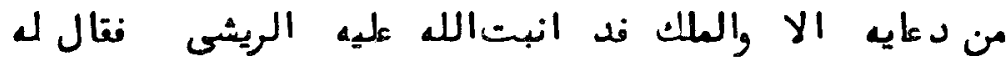

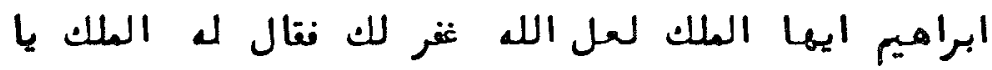

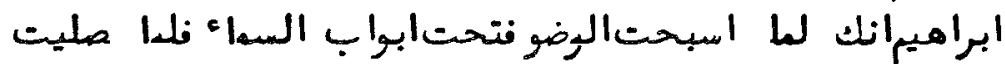

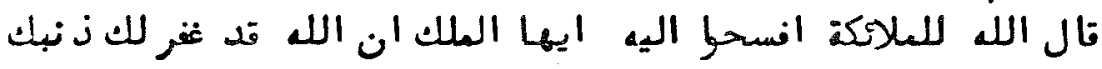

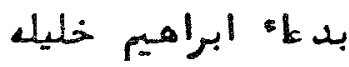


que no me hería en este lugar sino tú. Y dixo Ibraím: - ¿Cuánto abe qu'estás en este mundo? Dixo ella: - Abe cuatro mil años. Dixole Ibrahīm: —¿De qué te probiendas ye abe? Dixo ella: - Allah, ta ${ }^{\complement}$ ālà, me enbía cada día una abe, y en su pico un peç, y de aquesto me probiendo. Dixo Ibrahìm: - Feçme a saber por aquesta çibdad, y que a seído / $125 \mathrm{v} /$ su fecho? Dixo ella: -No lo sé más que tú, sino por lo que me fizo a saber mi ermana que bibió muy grande tienpo, que en su tienpo que ella bibió que conoció una bieja de muy grande tienpo, de los desta çibdad, que la saibó Allah de lo que deballó sobrellos, que no quedó ninguno sino aquella bieja, y dixo que los $/ 126 \mathrm{r} /$ desta çibdad eran que no mandaban con la raçón, ni se debedaban de nenguna cosa esquiba, y mandó Allah sobrellos una boz que murieron todos mas presto que pestañada de ojo. Y dixo Ibrahìm: - Ye mi señor, aqueste es el milagro que me prometĩste que me demostrarías. $Y$ enbió Allah a él y dixo /126v/ Bes más adelante, ye Ibrahim, y demostrate[é] mayor milagro que no ese. Y fuese Ibrahīm su camino, y bio un enbre qu'estaba su cabeça en el çielo y sus piedes en la tierra, y su senblança era senblança de persona, y el tenía dos alas, y el lloraba y sospiraba, y dezía: - Da parçida de mis pecados $/ 127 \mathrm{r} /$ y perdóname, ye perdonador de todas las cosas. Y dio aççalem sobrel Ibrahīm y dixo: - sobre tú sea el aççalem, ye amigo del piadoso. Y dixo Ibrahìm: - ¿Quien te a fecho saber que yo soy amigo del piadoso? Dixo el onbre: - Ye Ibrahìm, albriçiome mi señor que no me bería en este lugar nenguno sino tú. Dixo Ibrahîm: $/ 127 \mathrm{v} /$ ¿Quién eres tú? Dixo: - Yo soy un almalaque de los alamaques del $a l$-hağ $a b$, y adelantóseme un almalaque con un ataçabih, por aquello me a maldezido mi señor, y me daballó a la tierra, y yo le demando perdón tiempo abe de seis mil años, y no me a perdonado. Yo te demando, ye Ibrahìm, por amor de Allah, aquel que te tomó por amigo, que ru $/ 128 \mathrm{r} / \mathrm{eg}[\mathrm{u}] \mathrm{es}$ ada Allah por mí, que por bentura Allah me perdonará. Laora tomó al-wudū Ibrahìm, y fizo așsala dos atraca $^{\star}$ as, y lebantó sus manos al cielo. Y no ubo acabado su rogaria cuando ya lo perdonó Allah. Dixo Ibrahĩm: - Ye almalaque, sepas que Allah te a perdonado. Dixo el almalaque: -Ye Ibrahīm, cuando tu acabes de tú al-waḍ̄ $/ 128 \mathrm{v} /$ se abrieron las puertas de los cielos, y cuando acabes de fazer açala (sic) dixo Allah y los almalaques: - Alegrate ye almalaque, que Allah te a perdonado por la rogaría de Ibrahîm. Y subió laora el 


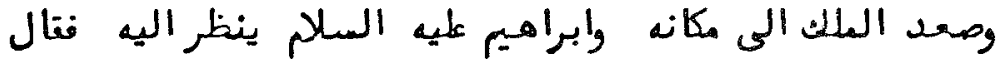

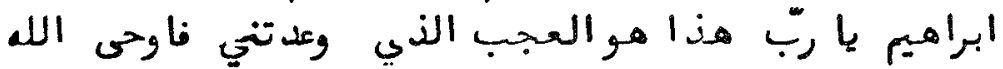

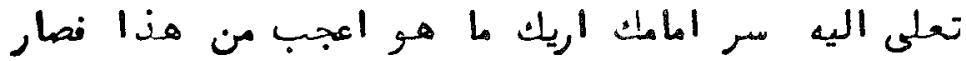

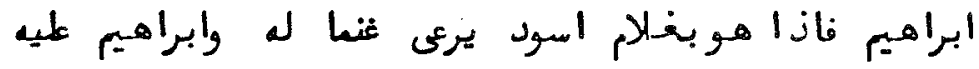

$$
\begin{aligned}
& \text { الهلام تف اشتد به العطن التي اليه وسلم عيه ابراهيه }
\end{aligned}
$$

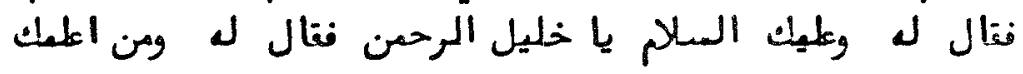

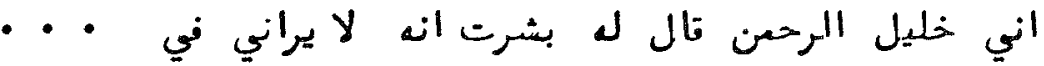

1 Sic por árabe clásico recurso para indicar cualidad más que cantidad. Véase $\mathrm{mi}$ artículo "The Arabic dialect of Valencia in 1595", AlAn, 36 (1971), 81-115.

${ }^{2}$ Sic. El texto aljamiado de la B.N.M., 5313 dice capa, y el manuscrito de Cuenca caja, aunque este último no es muy seguro.

${ }^{3}$ Se observará que la lista de procesos que hay un árabe no corresponde con la que encontramos en la traducción. Las traducciones moriscas dicen simplemente "muelen" allí donde el árabe dice y llan" y la segunda "muelen". Mucho agradezco al Dr. J.D. Latham por su ayuda en este pasaje, aunque en absoluto sea él responsable de mis errores. Para el estudio de las técnicas hispanoárabes de molienda, etc., recomiendo al lector el artículo de Latham, "Towards the interpretations of al-Saqati's observations on grain and flour-milling", Journal of Semitic Studies, 23 (1978), 64-87.

- Ms. $1+1 \%$

5 Sic.; cf. supra, nota 1.

6 Ms.

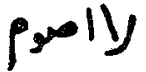

${ }^{7}$ Casi ilegible porque el manuscrito está dañado en esta parte.

- Árabe clásico. Crico

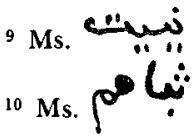


almalaque a su lugar. Dixo Ibrahím: -Ye mi señor, aqueste es el milagro que me dezias que me demostrarias /129r/ Y enbió Allah: - Ye Ibrahím, bes más adelante, y demostrarte[é] mayor milagro, y fuese su camino, y toposé con un mançebo negro que guardaba un ganado. $Y$ abía Ibrahím muy grande sed, y aplegose a él, y diole aççalem sobre él, y dixo el negro, sobre tú sea aç̧̧alem, ye amigo del piadoso /129v/ y dixo Ibrahím: - ¿Quién te ha fecho a saber que yo soy amigo del piadoso? Dixo el negro: -Albriçiome mi señor que no me bería en este lugar sino tú. Dixo Ibrahím: -Ye mancebo, dame a beber una bebida de agua. Dixo el mancebo: - Ye Ibrahím, sepas que no ay en mi poder gota de agua, enpero si quieres leche. Dixo: /130r/ - No quiero leche. Dixo el mancebo: -Anda con mí, ye Ibrahīm, y demostrate[é] a[g]ua. Y fuese Ibrahím con él fasta que llegaron a un cabeço de un monte, y posose cabo una piedra, y firió en ella el mançebo con sus piedes, y carpiose la piedra, y salió de ella una fuente de muy buena agua. Dixo el mançebo: $/ 130 v /$-Ye Ibrahim, toma al-wadū. Y dixo Ibrahim: -Ye mancebo ¿es (sic) de los almalaques o de los anabíes? Dixo el mancebo: -Ye Ibrahìm, no soy de los almalaques ni soy de los anabíes, empero quien obedeçe ada Allah, toda cosa abebdeçese Allah a él. Dixo Ibrahim: - Ye mi señor, aqueste es el milagro que me /13lr/ prometiste que me demostrarias. Y enbió Allah a él: -Bes ye Ibrahim más adelante, y demostrarte[é] otro milagro mayor que no ese que as bisto. Y fuese Ibrahim, y apartado del camino abía un bosque muy grande, y oyó un lloro muy triste, y fue enta donde oyó un lloro, y falló un onbre que fazía assala en la mar, $/ 130 \mathrm{v} /$ que llegaba ell agua fasta su garganta, y dixo Ibrahím, 'alayhi aççalem: -Ell aççalem sea sobre ti (sic), ye alabid. Y dixo el onbre. - Sobre tú sea l'aççalem ye amigo del piadoso. Dixo Ibrahim: - ¿Quién te a fecho a saber que yo soy amigo del piadoso? Dixo: - Albriçiome mi señor que no me bería en aqueste lugar /132r/ sino tú. Dixo Ibrahim: -Dime ¿̨cuánto abe qu'estás en este lugar? Dixo: - Abe ciento y cuarenta años. Dixo Ibrahim: - ¿De qué te probiendas? Dixo: - Cuando amanece Allah, enbia a mí una ahe que trae en su pieo una torta de pan, y con aquello paso. Dixo Ibrahim: - ¿De dónde as agua para beber? /132v/ Dixo: - Cuando e sed, fiero con mi pied sobre aquesta piedra, y salle della un ojo de agtua, y sube a mi boca, y no se mescla la duçe con la 
salada. Y dixo Ibrahim, y marabillose dello: -Ye mi señor, quería que me demostrases la grada de este sierbo que tienes en tu poder. Y enbió Allah a Ibrahìm que fuese $/ 133 \mathrm{r} /$ ada aquel sierbo que le fiziese a saber qu'era de los del fuego. Y laora marabillose Ibrahim de aquello, y fuese a el, y dixole: -Albriçiote de partes de mi señor, ca tu eres de los del fuego. Dixo el 'abid:

- Ye Ibrahim, ruégote con Allah que rueg[u]es por mi a tu señor, por bentura Allah me perdonara por tu rogaría. /133v/ Dixo Ibraim: - Plazeme. Y laora tomo alwador (sic), y fizo dos arracas de așąala, y rogó ada Allah que lo perdonase, y dezía el onbre: - Ye señor, ruégote que si juzgas que yo baya al fuego, fez el fuego de mi anpleza y de mi larg[u]eza y no tormentes sino a mí. Y laora ubo piedad Allah [laguna]

Allah a todos los

muçlimes y muçlimas por su piadad. (sic) Amín, ye rab alc alamina.

En Allah creo y estribo, cuerpo y alma le encomiendo, pues sin él todo es perdido. Yo lo digo, y es muy cierto.

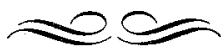


Texto tan extraordinario pide un comentario y una explicación. Debo confesar que al encontrarme por vez primera frente al manuscrito de Cuenca, no quise creer lo que veían mis ojos. En la parte que corresponde a la conversación de Ibrahim y la rana - según me consta ahora- creí entonces que estaba leyendo mal la palabra rana. Me dejé convencer de que ésa era la palabra sólo después de un estudio cuidadoso de la letra. El cotejo de los textos árabe y el aljamiado confirman esta lectura.

Si en el cuento hay una rana que habla, edebemos pensar que tenemos que ver con un mero cuento de hadas? Los cuentos de hadas, desde luego, aún en la forma tan degradada en que sobreviven hoy en día en la literatura infantil de tipo comercial, no han dejado de ser medios poderosos para transmitir mitos antiguos. Creo poder concluir con alguna certeza que este cuento no se narró simplemente para entretener a los niños; lo afirmo porque: $a$ ) se asocia en los tres manuscritos conocidos con otros textos de naturaleza exclusivamente devocianaria o religiosa. El contenido de los cuadernillos de Cuenca queda descrito arriba. El manuscritoárabe de Madrid contiene tradiciones islámicas. El manuscrito aljamiado de Madrid (núm. xlviii en el Catälogo de Guillén de Robles) tiene un $Q u$ r'än, abreviado, con otros doce textos piadosos, de los cuales, el núm. 2, "trata de resolución de diversas cuestiones morales y religiosas"; otra es la "Rogaría de la nube" (núm. 12), y el resto son cuentos de naturaleza moralizante, tales como la "Relación de lo que sucede en el sepulcro a quien observa o abandone la azzala (oración)" (núm. 4); y el relato que concierne a Ibrahim (núm.9).b) El mero hecho de poseer textos islámicos de cualquier naturaleza era extremadamente peligroso en la España del siglo XVI. Los cuadernillos de Cuenca son como un último resto, dolorosamente breve, de la religión islámica. Apenas puedo imaginar que un morisco haya copiado, junto a un calendario religioso, un cuento que conservó para su solaz. c) Sabemos, por la Suma de los principales mandamientos y devedemientos de la ley y çunna de Yçe de Gebir (quizá el texto más autorizado para la información sobre la fe islámica y su práctica en Castilla en el siglo XV), que los relatos que conciernen a Ibrahim están relacionados con el 'id al' 'adhạa: "Assí mesmo harán en la Pascua de las adeheas, nombrando en la primera alhotba la ibantaja de las adaheas, acordando a los creyentes el fecho de Ybráhim y de su hijo Izmael los bienaventurados" (véase Memorial histórico español, t. 5, Madrid, 1853, p. 293).

Por las razones expuestas, creo que el texto tenía valor religioso para los lectores moriscos. Antes de que podamos emprender un estudio completo de su valor religioso, necesitaremos saber mucho más acerca de todo el corpus de estos escritos tales como circulaban en España. He explorado, no con mucha profundidad, en las ediciones modernas de las Qisas al-anbiya, pero no he encontrado un 
paralelo a los textos que se refieren a Ibrahim. Sin embargo, como dice T. Nagel. s.v. Al-Kisá'ī en la Encyclopedia of Islam: "Investigaciones recientes prueban que las vidas de los profetas según aparecen en los numerosos manuscritos de los Kisas al-anbiyä de al-Kisá'í pertenecen a la tradición de la cuentística popular del Islam medieval. Sería inútil buscar un autor al-Kisá'í que hubiera escrito los Kișas en una fecha determinada. Es una figura tan vaga como el narrador al-Asmá'i en el cuento de «Antar»". En vano buscaríamos, añade, "un texto estándar de las leyendas". Queda claro, entonces, que el problema es complejo y equiparable en su dificultad con la investigación de las crónicas medievales dentro del campo de los estudios hispánicos ${ }^{11}$.

Naturalmente, hay otras maneras de acercarse al cuento y otras interpretaciones posibles. No es necesario tener conocimientos profundos de la antropología estructural según la escuela de LéviStrauss para ver que podríamos analizar la leyenda como un complejo en buena medida estructurado por esquemas de referencia a los distintos modos de preparar y consumir comida y bebida. El más notable de estos esquemas es la oposición entre Ibrahim, consumidor de pan de cebada (y experto en todas las etapas de su producción), y el santón, exclusivamente carnívoro: esquema en el que se plasma la viejísima disputa entre sociedades de cazadores y sociedades de agricultores. La pregunta “¿De qué te probiendas?” se repite a lo largo del texto entero. En un relato que corría en la Península ibérica, es curioso el dato de un pastor negro que se alimentaba con leche. Podemos descartar la posibilidad de que esa información-etnográficamente bien fundada- se base en conocimientos directos de las regiones del Âfrica negra en donde vivían esos pastores. El cuento debe haberse difundido por lo tanto a través de una larga cadena de transmisión, no necesariamente escrita.

Quizá más notable aún es un detalle que parece invitarnos a adoptar una teoría antropológica más vieja, la difusionista de Frazer. Estoy pensando en la extraña historia del santón, que, después de comer el carnero, reúne los huesos, los coloca en la piel y revive al animal. Parecidas creencias se encuentran en partes del mundo muy

11 En la literatura, relativamente abundante, sobre el profeta Ibrahim, no he encontrado aún referencias del interés por el profeta en la España islámica. Los textos básicos son, por supuesto, ath-ThaClabi, Qisas al-anbiya (he consultado la edición A.H. 1312 del Cairo, véase especialmente p. 43) y al-Kasā'ĩ, Qisas al-anbiyä (consulté una edición sin fecha en la biblioteca de la School of Oriental and African Studies de Londres, pp. 128-14, y la edición de Eisenberg, Leiden, 1922). Un estudio general de gran utilidad es el de D. SIDERSKY, Les origines des légendes musulmanes dans le Coran et dans les vies des prophetes", Paris, 1933. Si aceptamos el punto de vista de Nagel, deberemos extender nuestra búsqueda a otras formas de literatura popular. En su artículo, "An allegory from the Arabian nights: The city of Brass", $B S O A S, 34$ (1971), 9-19, Andreas Hamori trata, entre otras cosas, el tema de la ciudad cuyos habitantes han muerto (p. 13), tema importante en relación con nuestro texto. En Mélanges de la Faculté Orientales de l'Université Saint Joseph, 4 (1910), p. 46, dijo el p. Cheiko: "Nous souhaitons en terminant qu'un ou plusieurs orientalistes consacrent leur temps a l'étude de ees Apocryphes. C'est une littérature fort curieuse qui leur réserve beaucoup de surprises". 
lejos la una de la otra, entre pueblos cazadores, quienes, de esta manera, procuran asegurar la abundancia de la caza. Uno Harva, en Die religiösen Vorstellung der altaischen Völker (Helsinki 1938), publicó fotografías de plataformas construidas adrede para conservar los huesos de animales salvajes (p. 434); y Áke Hultkranz, en su libro Conceptions of the soul among North American Indians (Estocolmo, 1953) dice: "Como se sabe, estas tribus [los apaches jicarilla] consideran que la preservación de los huesos (de preferencia puestos en el orden anatómico que les corresponde) es garantía de que la presa resucitará" (p. 175).

¿Cómo llegó este cuento a la Península ibérica, y por qué lo conservó la comunidad morisca? No podemos pensar en un propósito funcional porque los moriscos nunca fueron cazadores. Si tuviéramos que clasificarlos según una oposición binaria en tre cazadores y agricultores, los moriscos serían clasificados, sin duda alguna, como agricultores, y en este cuento Ibrahim es un agricultor. Pero en la Península ibérica los moriscos no se encontraban en conflicto con cazadores, sino con ganaderos y pastores, es decir con los cristianos transhumantes. Este aspecto del problema morisco está muy descuidado, aunque ya en 1919, G. M. Amando Melón y Ruiz de Gordejuela lo estudió muy bien en su tesis doctoral, Lupercio Latrás y la guerra de moriscos y montañeses en Aragón a fines del siglo xyi.

Hasta que el profesor loan Lewis me lo hizo notar, no me había dado cuenta de que no existía en el texto referencia explícita a Mahoma o al Islam. Creo que el detalle se me había escapado porque todo el vocabulario utilizado es islámico. Si damos importancia al hecho de que Mahoma no se menciona, podríamos considerar el texto como muestra de un cambio hacia alguna forma de sincretismo, hacia un Islam en el que no encuentran ya los aspectos religiosos menos aceptables para los cristianos. Pensamos, inevitablemente, en el sincretismo religioso creado en Granada en 1590 por los falsificadores de los libros plúmbeos del Sacromonte, que nos dieron un cristianismo del que estaban ausentes aspectos como la divinidad del hijo y la comunión con el vino que tanto repugnaba a la piedad musulmana. Este texto de Ibrahim es demasiado breve como para que saquemos alguna conclusión. Otros textos moriscos del mismo estilo deben considerarse dentro del contexto del Islam medieval tardío en general. No sería difícil traer a cuenta otros documentos moriscos en donde no sólo se menciona al Profeta, sino que se celebran sus obras y su persona. Por fin, en lo que respecta al profeta Ibrahim, debemos recordar que hay muestras de reverencia hacia su persona profundamente arraigadas en las formas más ortodoxas del Islam (aunque en el nivel más arcaico, el del mismo Qu'rān, el problema de la interpretación correcta del término hanif trae problemas, en lo que hace al sincretismo, y no hay consenso entre los especialistas para resolver el conflicto). 
Los cuadernillos de Cuenca y su historia, a pesar de su naturaleza framentaria y de su escritura torpe, son pruebas valiosas de los esquemas de la vida interior de la comunidad morisca. Ahora que los especialistas prestan más atención a la historia de las mentalidades, no podemos darnos el lujo de ignorar material como éste. Los inquisidores que conservaron estos fragmentos no estaban, al parecer, muy seguros de su verdadera naturaleza, pero Baltasar Ortiz tenía razón cuando dijo "¡Cuerpo de Dios. Esto es cosa de moros!" Había dado con un documento muy importante.

L. P. HARveY

University of London, King's College.

\section{AGRADECIMIENTO}

El trabajo de archivos para preparar este estudio se realizó con la ayuda de una beca de investigación de la British Academy, y quiero agradecer a los. que administran el Fund for Small Research Grants in the Humanities. Gracias a la Dra. Mercedes García Arenal (y a su excelente estudio La Inquisición y los moriscos: los procesos del tribunal de Cuenca, Madrid, 1978), por haber llamado mi atención sobre los documentos de Cuenca. Agradezco también el Canónigo Archivero del Archivo Diocesano de Cuenca, fray Dimas Pérez Ramírez, así como la cuerpo de la sección de manuscritos de la Biblioteca Nacional de Madrid, por su generosa ayuda y cortesía. Mucho aproveché de las discusiones que tuve con el profesor Arthur Hatto sobre las primeras versiones de este artículo (a él debo las referencias sobre la costumbre de los cazadores de conservar los huesos), con el profesor loan Lewis, la Dr. La Fontaine, y los miembros del seminario del departamento de Antropologia Social de la London School of Economics. Cualquiera error u omisión es, naturalmente, de mi entera responsabilidad. 